Agr. Biol. Chem., Vol. 27, No. 6, p. 461 466, 1963]

\title{
Chemical Studies on Amino-Carbonyl Reaction
}

\author{
Part II Identification of D-Glucosone Formed by Oxidative Browning \\ Degradation of N-D-Glucoside
}

By Hiromichi Kato

Department of Agricultural Chemistry, Faculty of

Agriculture, University of Tokyo

Received March 4, 1963

\begin{abstract}
From the browning degradation mixture of N-D-glucosyl- $n$-butylamine in methanol solution neutralized with acetic acid, D-glucosone was isolated and identified as its 2,4-dinitrophenylosazone, in addition to the 3-deoxy-D-glucosone which had been proved as an intermediate substance of browning reaction ${ }^{1,2)}$, although the yield of $\mathrm{D}$-glucosone was far less than that of 3-deoxy-D-glucosone. Under bubbling with air, the yield of D-glucosone considerably increased, indicating that its formation depended upon the oxygen dissolved. DGlucosone is regarded as an important intermediate for browning, and a mechanism for its formation from $\mathrm{N}$-glucoside is proposed.
\end{abstract}

D-Glucosone has been obtained in the forms of osazones by the oxidation of D-glucose, $\mathrm{D}$ mannose, or D-fructose with hydrazines, and also yielded in the free form by the direct oxidation of the sugars by such reagents as that of Fenton ${ }^{3)}$, cupric acetate ${ }^{4)}$, selenious $\operatorname{acid}^{5)}$, etc., and by the oxidative decomposition of 1-deoxy-1- $p$-toluidino-D-fructose by hydrazine $^{6,7)}$. In alkaline solution, air (or oxygen) degrades a sugar to the aldonic acid containing one carbon atom less than tile substrate sugar ${ }^{8,9)}$. In this decomposition, the corresponding osone, which is possibly formed from the 1,2-enediol of the sugar, has been regarded as an intermediate ${ }^{10)}$. In neu-

\footnotetext{
1) Part I: H. Kato, This Journal, 26, 187 (1962).

2) H. Kato, ibid., 24, 1 (1960).

3) R.S. Morrell and J.M. Crofts, J. Chem. Soc., 75, 786 (1899).

4) W.L. Evans, W.D. Nicoll, G.C. Strause and C.E. Waring, J. Am. Chem. Soc., 50, 2267 (1928)

5) K.C. Dixon and K. Harrison, Biochem. J., 26, 1954 (1932)

5) F. Weygand and A. Bergmann, Chem. Ber., 80, 255 (1947).

7) Y. Inoue, K. Onodera and I. Karasawa, J. Agr. Chem. Soc. Japan, 25, 75 (1951).

8) J.U. Nef, Ann., 403, 204 (1914).

9) N.K. Richtmyer, R.M. Hann and C.S. Hudson, J. Am. Chem. Soc., 61, 340, 343 (1939).

10) S. Bayne and J.A. Fewster, "Advances in Carbohydrote Chemistry ", edited by M.L. Wolfrom, Academic Press, New York, 1956,
} Vol. 11, p. 59. tral, or acidic solution without specific catalysts, however, it has not been shown that air can dehydrogenate sugars to the corresponding osones.

In the previous papers ${ }^{1,2)}$, it was indicated that $\mathrm{N}$-glycosides was easily decomposed to form melanoidins by weak acid catalysis, and that the corresponding 3-deoxyosone, a dehydrated product of the sugar, was recognized as an intermediate. In the present paper, the formation of D-glucosone from N-D-glucoside in neutral solution by air oxidation is investigated. The method of identification is described below.

$\mathrm{N}$-D-Glucosyl- $n$-butylamine was dissolved in methanol, neutralized with acetic acid, and heated at $65^{\circ} \mathrm{C}$ for thirty minutes under ordinary atmosphere. The resulting dark brown solution was diluted with water, decolorized with active carbon, and decationized with a cation-exchange resin. To the colorless filtrate a sulfuric acid solution of 2,4- 


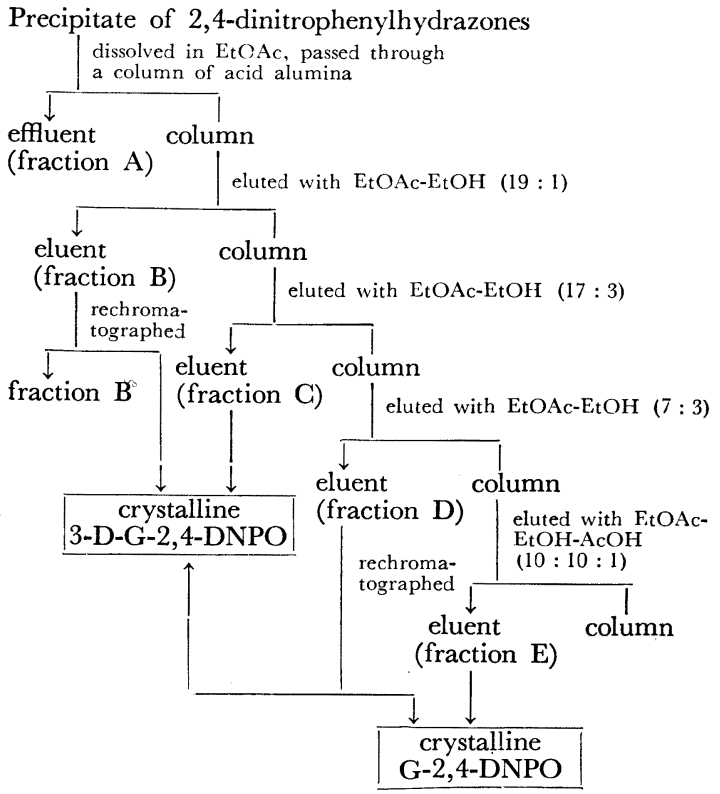

FIG. 1. Separation of Highly Hydroxylated 2,4Dinitrophenylhydrazones by Column Chromatography dinitrophenylhydrazine ${ }^{11}$ was added. After thirty minutes at room temperature, the precipitate of hydrazones formed was collected. The mixture of hydrazones was separated into several fractions on a column of acid alumina, and the fractions, which contained 3-deoxy-Dglucosone 2,4-dinitrophenylosazone (3-D-G2,4-DNPO) and D-glucosone 2,4-dinitrophenylosazone (G-2,4-DNPO), were further purified. The outline of the procedure of column chromatography is given in Fig. 1. Thus, 3-D-G-2,4-DNPO (m.p. $251^{\circ} \mathrm{C}$, dec.) and G2,4-DNPO (m.p. $253^{\circ} \mathrm{C}$, dec.) were isolated, although the yield of the latter was far less than that of the former. These osazones were identified by the mixed melting points with the authentic specimens and by the comparisons between their infrared spectra (Fig. 2).

D-Glucosone was also isolated from the mixture of D-glucose and glycine as follows. DGlucose and glycine were dissolved in water, neutralized to $\mathrm{pH} 6.5$ with sodium bicarbo-

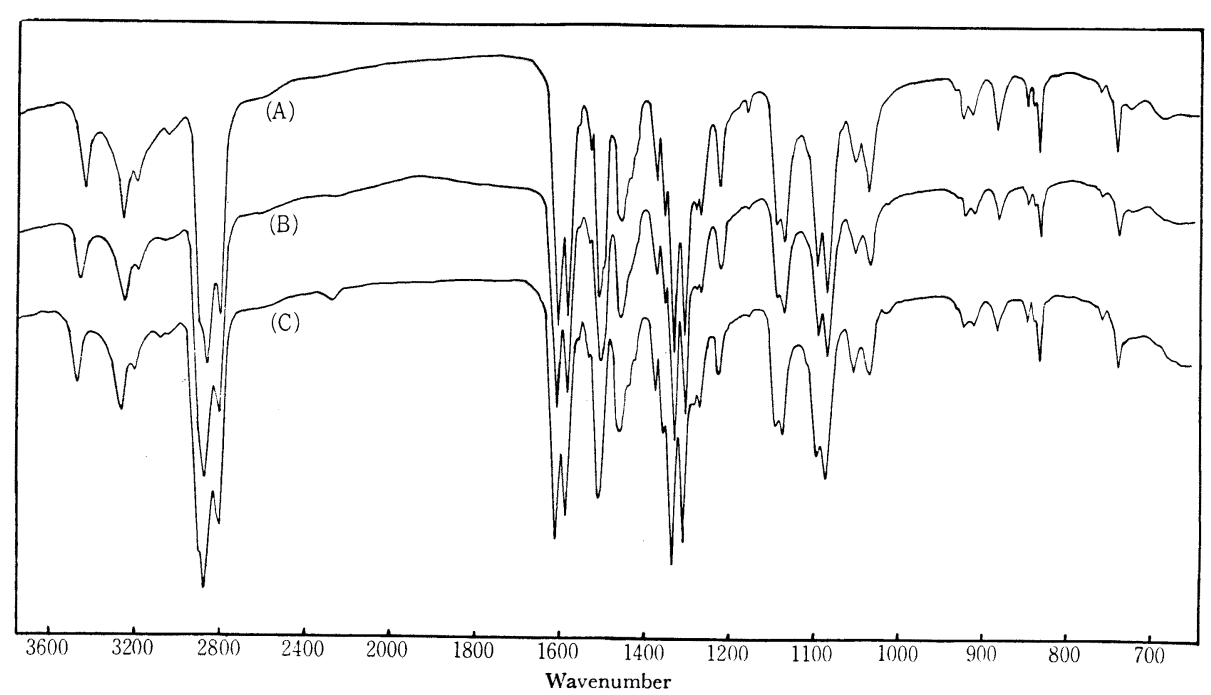

FIG. 2. Infrared Spectra of D-Glucosone 2,4-Dinitrophenylosazone (G-2,4-DNPO).

(A) Authentic G-2,4-DNPO.

(B) Isolated from browning degradation mixture of $\mathrm{N}$ - $\mathrm{D}$-glucosyl- $n$-butylamine undr bubbling with air.

(C) Isolated from browning solution of D-glucose with glycine at $\mathrm{pH} 6.5$.

11) R.L. Shriner, R.C. Fuson and D.Y. Curtin, "The Systematic Identification of Organic Compounds", John Wiley and Sons, New York, 1956 , p. 219 
TABle I. Formation of 3-DEOXY-D-GLucosone AND D-GLucosone IN BRowning DegRADATION OF D-GLUCOSE WITH $n$-BUTYLAMINE OR GLYCINE UNDER VARIOUS CONDITIONS

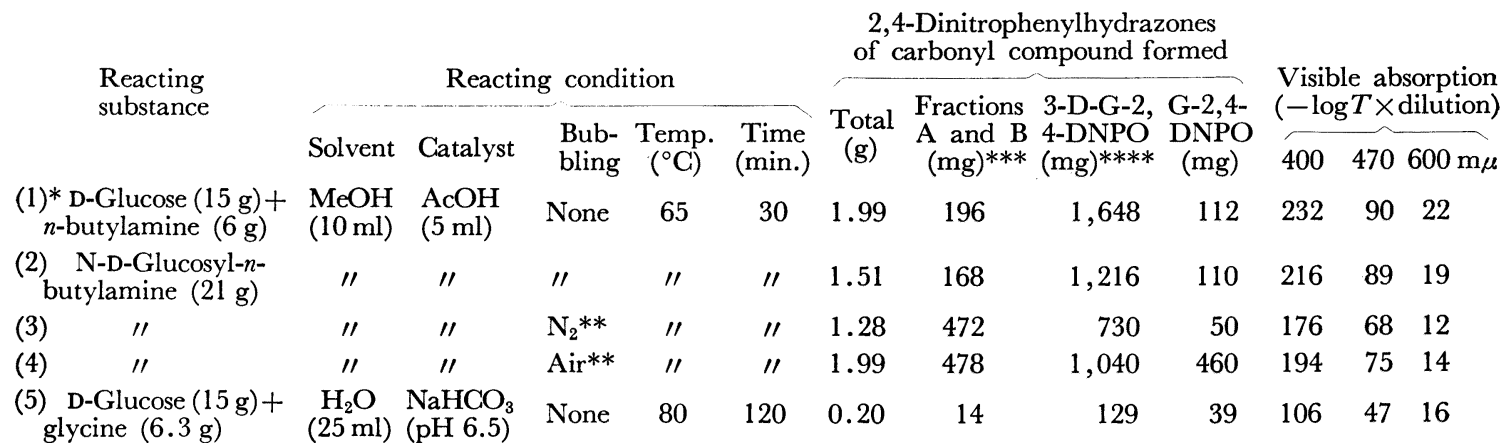

* Before adding acetic acid, the mixture was heated at $65^{\circ} \mathrm{C}$ for thirty minutes to prepare the solution of $\mathrm{N}$-glucoside.

** Bubbled at the speed of about $2 \mathrm{ml}$ per second.

*** Refer to the experimental part.

**** Monohydrated crystal.

nate, and heated at $80^{\circ} \mathrm{C}$ for two hours under ordinary atmosphere. The resulting reddish brown solution was treated similarly as described above to isolate the osazones. Both 3-D-G-2,4-DNPO and G-2,4-DNPO were identified.

When air was bubbled into the methanol solution of N-D-glucosyl- $n$-butylamine neutralized with acetic acid, the yield of D-glucosone could be increased several times. On the contrary, bubbling with nitrogen instead of air consiclerably reduced the yield of D-glucosone, as shown in Table I.

The experimental results described above indicate that the formation of D-glucosone from N-D-glucoside (I) depends upon the oxygen from the outside. In the previous papers $^{1,2)}$, as an intermediate to 3-deoxy-Dglucosone from I, the 1,2-enol form (II) of 1-amino-1-deoxy-D-fructose (III) was postulated. In the present experiment under oxidative condition, it is also postulated that, II, an enaminol structure, is susceptible to oxidation, forming an imino-osone derivative (IV), from which D-glucosone (V) is liberated.

Since osone is a dicarbonyl compound as well as 3-deoxyosone, indicating closely simi-

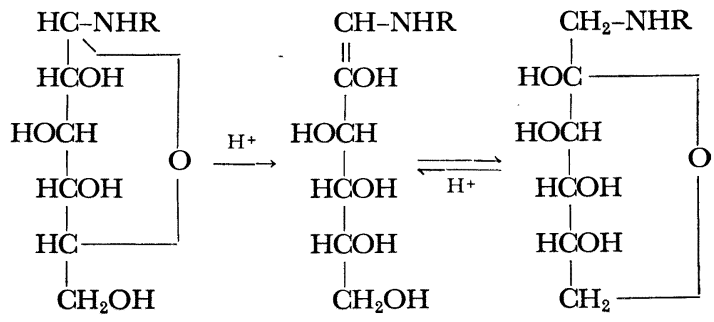

I

II

III<smiles>[R]N=C(C(=O)C(O)C(O)C(O)CO)C(O)C(O)C(O)C(O)C(=O)C=O</smiles>

$\mathrm{R}=n$-butyl.

lar reactivities ${ }^{12)}$, it is also regarded as an intermediate of melanoidin formation.

1-Deoxy-1- $n$-butylamino-D-fructose, the Amadori rearrangement product, was prepared as

12) D.L. Ingles, Aust. J. Chem., 14, 302 (1961). 
follows. An methanol solution of N-D-glucosyl- $n$-butylamine neutralized with acetic acid was heated similarly as described above. After decolorizing it with active carbon, the filtrate was adsorbed to a column of Dowex 50-X4 and followed by the elution with $4 \mathrm{~N}$ hydrochloric acid. From the eluent, 1-deoxy-1-nbutylamino-D-fructose (III) was obtained and characterized as its hydrochloride in the theoretical yield of $36 \%$.

This Amadori rearrangement product (III) and the N-D-glucoside (I) were compared with respect to their browning reactivities, as shown in Table II. In methanol solution neutralized with acetic acid at $65^{\circ} \mathrm{C}$, III was very stable, causing no browning reaction. However, the substitution of a half part of I for III, i.e. the mixture of a half part of I and a half part of III, caused browning reaction as strong as the $\mathrm{I}$ alone. On the other

TABLE II. A COMPARISON OF THE BROWNINING REACTIVITIES OF N-D-GLUCOSYL- $n$-BUTYLAMINE AND ITS AMADORI REARRANGEMENT PRODUCT

Reacting
substance*
N-D-Glucosyl- $n$ -
butylamine- $\mathrm{H}_{2} \mathrm{O}$
$\mathrm{AcOH}$
$\mathrm{NaCl}$
$\mathrm{H}_{2} \mathrm{O}$

(B) N-D-Glucosyl- $n$ butylamine- $\mathrm{H}_{2} \mathrm{O}$ 1-Deoxy-1- $n$-butylamino-D-fructose-HCl $\mathrm{AcONa}-3 \mathrm{H}_{2} \mathrm{O}$ $\mathrm{AcOH}$

\begin{tabular}{|c|c|c|c|}
\hline \multirow{2}{*}{$\begin{array}{l}\text { Gram } \\
\text { mole }\end{array}$} & \multicolumn{3}{|c|}{$\begin{array}{l}\text { Visible absorption } \\
(-\log T \times \text { dilution })^{* *}\end{array}$} \\
\hline & 400 & 4706 & $600 \mathrm{~m} \mu$ \\
\hline $2 \times 0.0088$ & \multirow{2}{*}{39.8} & \multirow[b]{2}{*}{18.1} & \multirow[b]{2}{*}{5.65} \\
\hline $\begin{array}{r}2 \times 0.0088 \\
0.0088 \\
2 \times 0.0088\end{array}$ & & & \\
\hline 0.0088 & \multirow{3}{*}{40.7} & \multirow{3}{*}{17.4} & \multirow{3}{*}{5.15} \\
\hline 0.0088 & & & \\
\hline $\begin{array}{l}0.0088 \\
0.0088\end{array}$ & & & \\
\hline 0.0088 & \multirow[b]{2}{*}{6.50} & \multirow[b]{2}{*}{2.91} & \multirow[b]{2}{*}{0.82} \\
\hline $\begin{array}{r}0.0088 \\
0.0088 \\
3 \times 0.008\end{array}$ & & & \\
\hline 0.0088 & \multirow[b]{2}{*}{0.46} & \multirow[b]{2}{*}{0.13} & \multirow[b]{2}{*}{0.03} \\
\hline $\begin{array}{l}0.0088 \\
0.0088\end{array}$ & & & \\
\hline $\begin{array}{l}\text { thanol. Th } \\
\text { o the amino } \\
\text { e and water }\end{array}$ & quant & $\begin{array}{l}\text { of aceti } \\
\text { each se } \\
\text { in eacl }\end{array}$ & $\begin{array}{l}\text { tic acid } \\
\text { section. } \\
\text { ch sec- }\end{array}$ \\
\hline
\end{tabular}

hand, a half amount of I caused only slow browning reaction.

These results show that, when III, a stable compound, is mixed with $\mathrm{I}$, browning reaction occurs in which III is involved, indicating that the formation mechanisms of 3-deoxyosone and osone are much complicated.

\section{EXPERIMENTAL}

Melting points were uncorrected. For absorption measurements in visible and ultraviolet regions, Cary Model 14 Auto-recording Spectrophotometer was used. Infrared spectra were recorded on Kōken DS-301 Infrared Spectrophotometer in Nujol mull. N-DGlucosyl- $n$-butylamine was prepared by the method of the previous paper ${ }^{2}$.

Column Chromatography of Highly Hydroxylated 2,4Dinitrophenylhydrazones.

(a) Adsorbent. Acid alumina ${ }^{13)}$ was prepared as flolows. Alumina (Merck) was suspended in $2 \mathrm{~N}$ sulfuric acid and allowed to stand overnight, filtered and washed with water until $\mathrm{pH}$ of the washings became 5, and it was dried at $105 \sim 110^{\circ} \mathrm{C}$ for one day. Ten grams of acid alumina was used per $50 \mathrm{mg}$ of hydrazone. The diameter of column was $10 \mathrm{~mm}$ for $10 \mathrm{~g}$ of acid alumina and $18 \mathrm{~mm}$ for $50 \mathrm{~g}$ of it. Acid alumina was suspencied in ethyl acetate and packed in a column.

(b) Chromatography. Mixture of 2,4-dinitrophenylhydrazones was completely dissolved in hot ethyl acetate. G-2,4-DNPO was less soluble and needed a large volume of the solvent. The solution was feeded to a column of acid alumina, and then the column was washed with ethyl acetate. The effluent and washings were combined and evaporated (fraction A). The column was then eluted in sequence as follows: eluted with ethyl acetate-ethanol (19:1) (fraction B), eluted with ethyl acetate-ethanol (17:3) (fraction C), eluted with ethyl acetate-ethanol $(7: 3)$ (fraction D), and eluted with ethyl acetate-ethanol-acetic acid $(10: 10: 1)$ (fraction E). Each fraction was evaporated to dryness by surface evaporation. From fraction C, 3-D-G-2,4-DNPO was obtained as monohydrated crystal, and from fraction $E$, micro-crystalline G-2,4-DNPO was obtained. Fraction B occasionally contained a small quantity of 3-D-G-2,4-DNPO, and

13) H. Kato, Y. Yamada, K. Izaka, and Y. Sakurai, J. Agr. Chem. Soc. Japan, 35, 412 (1961). 
so was rechromatographed to separate it. Fraction D was a mixture of 3-D-G- and G-2,4-DNPO, accordingly the fraction was rechromatographed to separate them. Fraction E, if it was impure, was rechromatographed. Fractions $\mathrm{A}$ and $\mathrm{B}$ contained the hydrazones of carbonyls which had two or less hydroxyl groups, and in the present paper, these fractions were not investigated. 3-D-G-2,4-DNPO isolated from fractions B, C, and $\mathrm{D}$ as clescribed above was combined and weighed. Similarly G-2,4-DNPO from fractions $D$ and $E$ were combined.

Identification of 2,4-Dinitrophenylosazones of 3Deoxy-D-glucosone and D-Glucosone. Authentic 3-DG-2,4-DNPO was prepared as the crystal of monohydrate from 3-deoxy-D-glucosone, which was isolated by the method of the previous paper ${ }^{1)}$. Authentic G-2,4-DNPO was prepared from D-glucosone, which was liberated by the degradation of D-glucose phenylosazone $^{14)}$. Melting point and mixed melting point with authentic specimen were determined for each sample. But, the melting points of 3-D-G-2,4-DNPO (m.p. $253^{\circ} \mathrm{C}$, dec.) and G-2,4-DNPO (m.p. $254^{\circ} \mathrm{C}$, dec.) were close, and the mixed melting point of them was $248^{\circ} \mathrm{C}$ (dec.), therefore, for definite identification, infrared absorption spectra were recorded for each sample.

Formation of D-Glucosone in Browning Degradation Mixture of N-D-Glucosyl-n-butylamine.

(a) From $\mathrm{D}$-Glucose and $\boldsymbol{n}$-Butylamine. A mixture of powdered anhydrous D-glucose (15 g), $n$-butylamine $(6 \mathrm{~g})$ and methanol $(10 \mathrm{ml})$ was heated at $65^{\circ} \mathrm{C}$ for thirty minutes with stirring to prepare a concentrated solution of N-D-glucosyl-n-butylamine. The viscous solution was cooled to room temperature and glacial acetic acid $(5 \mathrm{ml})$ was adcled and it was heated at $65^{\circ} \mathrm{C}$ for thirty minutes under ordinary atmosphere. Browning degradation of N-D-glucosyl$n$-butylamine occurred. The resulting dark solution was cooled, diluted with water, decolorized with active carbon, and decationized on a column of Dowex 50-X4 (H-form). The effluent was treated with a sulfuric acid solution of 2,4-dinitrophenylhydrazine $(3.2 \mathrm{~g})^{11)}$. After thirty minutes at room temperature, it was filtered with suction and the precipitate of hydrazones was washed with $2 \mathrm{~N}$ hydrochloric acid and water, and dried. An amount of $1.99 \mathrm{~g}$ of hydrazones was obtained. Separation by column chromato-

14) E. Fischer, Ber., 22, 87 (1889). graphy gave $1,648 \mathrm{mg}$ of 3-D-G-2,4-DNPO monohydrate (m.p. $251^{\circ} \mathrm{C}$ ) and $112 \mathrm{mg}$ of G-2,4-DNPO (m.p. $253^{\circ} \mathrm{C}$ ).

(b) From N-D-Glucosyl-n-butylamine. The monohydrated crystal of $\mathrm{N}$-D-glucosyi- $n$-butylamine (21 g) was taken in a round-bottomed flask, and methanol $(10 \mathrm{ml})$ and glacial acetic acid $(5 \mathrm{ml})$ were added, and then it was heated at $65^{\circ} \mathrm{C}$ for thirty minutes under ordinary atmosphere. The resulting dark solution was treated similarly as in the case of (a). Separation of hydrazones $(1.51 \mathrm{~g})$ by column chromatography gave $1,216 \mathrm{mg}$ of 3-D-G-2,4-DNPO monohydrate (m.p. $251^{\circ} \mathrm{C}$ ) and $110 \mathrm{mg}$ of G-2,4-DNPO (m.p. $\left.253^{\circ} \mathrm{C}\right)$.

(c) From N-D-Glucosyl-n-butylamine under Bubbling with Air or Nitrogen. N-D-Glucosyl- $n$-butylamine $(21 \mathrm{lg})$ was heated similarly as in the case of (b) under bubbling with air at the speed of about $2 \mathrm{ml}$ per second. The resulting dark solution was also treated similarly. In this case, from the precipitate of hydrazones $(1.99 \mathrm{~g}), 1,040 \mathrm{mg}$ of $3-\mathrm{D}-\mathrm{G}-2,4-\mathrm{DNPO}$ monohydrate (m.p. $251^{\circ} \mathrm{C}$ ) and $460 \mathrm{mg}$ of G-2,4-DNPO (m.p. $253^{\circ} \mathrm{C}$ ) were isolated.

One more experiment was carried out for N-Dglucosyl- $n$-butylamine (21 g) under bubbling with nitrogen instead of air. From the precipitate of hydrazones $(1.28 \mathrm{~g}), 730 \mathrm{mg}$ of 3-D-G-2,4-DNPO monohydrate (m.p. $251^{\circ} \mathrm{C}$ ) and $50 \mathrm{mg}$ of G-2,4-DNPO (m.p. $253^{\circ} \mathrm{C}$ ) were isolated.

Formation of D-Glucosone in Browning Degradation Mixture of D-Glucose with Glycine. D-Glucose (15 g) and glycine $(6.3 \mathrm{~g})$ were taken in a round-bottomed flask and dissolved in water $(25 \mathrm{ml})$ and adjusted to $\mathrm{pH} 6.5$ with sodium bicarbonate, and then heated at $80^{\circ} \mathrm{C}$ for two hours under ordinary atmosphere. The resulting reddish brown solution was treated similarly as in the case of (a). Separation of hydrazones $(200 \mathrm{mg})$ by column chromatography gave 129 $\mathrm{mg}$ of 3-D-G-2,4-DNPO monohydrate (m.p. $251^{\circ} \mathrm{C}$ ) and $39 \mathrm{mg}$ of G-2,4-DNPO (m.p. $253^{\circ} \mathrm{C}$ ) .

Preparation of 1-Deoxy-1-n-butylamino-D-fructose Hydrochloride. Powdered anhydrous D-glucose (30 g), $n$-butylamine $(12 \mathrm{~g})$ and methanol $(20 \mathrm{ml})$ were heated at $65^{\circ} \mathrm{C}$ for thirty minutes with stirring. An orange yellow viscous solution of $\mathrm{N}$-D-glucosyl- $n$-butylamine was obtained. After cooling it with tap water, glacial acetic acid $(10 \mathrm{ml})$ was added and the solution was heated at $65^{\circ} \mathrm{C}$ for thirty minutes. The reacting solution became dark brown, then it was 
cooled, and diluted to a volume of about $300 \mathrm{ml}$ with water. After decolorizing it with active carbon, the pale yellow filtrate was treated with a column of Dowex 50-X4 (H-form, $100 \mathrm{~g}$ ). The effluent contained 3-deoxy-D-glucosone, D-glucosone, D-glucose which was formed by the hydrolysis of unreacted glucosylamine, D-mannose ${ }^{1)}$, and other decomposition products. The column was washed with water and then eluted with $4 \mathrm{~N}$ hydrochloric acid. The eluted fractions which reduced Fehling's solution were combined and neutralized to $\mathrm{pH} 5$ with $2 \mathrm{~N}$ sodium hydroxide. It was concentrated to dryness under reduced pressure, and absolute ethanol was added to it, and it was stirred, then allowed to stand. The precipitate of sodium chloride was filtered with suction and washed with absolute ethanol. The filtrate and washings were combined and concentrated to dry- ness to yield a crystallizing mass, to which $99 \%$ ethanot was added, ground, filtered, washed with $99 \%$ ethanol and dried. An amount of $13.1 \mathrm{~g}$, fine needles, m.p. $120^{\circ} \mathrm{C}$, was obtained. Second crop (3.2 g) from the filtrate and washings was yielded $(36 \%$ in total). In $0.05 \mathrm{~N}$ sodium hydroxide at room temperature, the compound rapidly reduced methylene blue, indicating to be an Amadori rearrangement product ${ }^{15)}$. Anal. Found: C, 44.42; H, 8.13; N, 5.31; Cl, 13.53. Calcd. for $\mathrm{C}_{10} \mathrm{H}_{21} \mathrm{NO}_{5} \cdot \mathrm{HCl}$ : C, 44.20; $\mathrm{H}, 8.16 ; \mathrm{N}, 5.16 ; \mathrm{Cl}$, $13.05 \%$.

Acknowledgements. The author wishes to express his sincere thanks to Prof. Dr. Y. Sakurai for his guidance throughout the work and also for his revision of the manuscript.

15) J.E. Hodge, J. Agr. Food Chem., 1, 928 (1953). 